\title{
Abdominal pregnancy-a case report
}

\author{
Indrani Roy*, Neha Choubey
}

Department Of Obstetrics and Gynaecology, Nazareth Hospital, Shillong, Meghalaya, India

Received: 24 July 2021

Accepted: 16 August 2021

\author{
*Correspondence: \\ Dr. Indrani Roy, \\ E-mail: indraniroydeb@gmail.com
}

Copyright: () the author(s), publisher and licensee Medip Academy. This is an open-access article distributed under the terms of the Creative Commons Attribution Non-Commercial License, which permits unrestricted non-commercial use, distribution, and reproduction in any medium, provided the original work is properly cited.

\begin{abstract}
Abdominal pregnancy is a rare obstetric complication with high maternal mortality and even higher perinatal mortality, and it can be primary or secondary with the latter being the most common type. This is a case of abdominal pregnancy in gravida 2, para 0+1 women admitted to the hospital with h/o amenorrhoea for two and a half months, with the chief complaints of pain abdomen for one week which was severe that day for which she attended emergency. Ultrasonography revealed a single live intra uterine pregnancy with a solid retro gestational sac collection, with a CRL of $11 \mathrm{~W} 3 \mathrm{D}$. She was initially managed conservatively. Surgical intervention became necessary on day $9^{\text {th }}$ when with the rising fundal height and drop in $\mathrm{Hb}$ levels, under general anaesthesia.
\end{abstract}

Keywords: Abdominal pregnancy, Laparotomy, Placenta previa, Serum beta Hcg

\section{INTRODUCTION}

Abdominal pregnancy has historically been defined as an implantation in the peritoneal cavity, exclusive of tuboovarian or intra-ligamentary pregnancy. ${ }^{1}$ Abdominal pregnancy is a rare obstetric complication with high maternal mortality and even higher perinatal mortality, and it can be primary or secondary with the latter being the most common type. Primary peritoneal implantation is rare. Studdiford established three criteria for diagnosing primary peritoneal pregnancies: (1) normal bilateral fallopian tubes and ovaries; (2) the absence of uteroperitoneal fistula, and (3) a pregnancy related exclusively to the peritoneal surface and early enough to eliminate the possibility of secondary implantation following a primary nidation in the tube. ${ }^{2}$ Secondary abdominal pregnancy is a condition where the embryo or foetus continues to grow in the abdominal cavity after its expulsion from the fallopian tube or other seat of its primary development. Secondary abdominal pregnancy almost always follows early rupture of a tubal ectopic pregnancy into the peritoneal cavity with the incidence being 1 in 10,000 live births. ${ }^{3}$ Advanced abdominal pregnancy is rare and accounts for 1 in 25,000 pregnancies. ${ }^{4}$ Risk factors for abdominal pregnancy are the same as for ectopic pregnancy and, when it is recognized, immediate laparotomy with removal of the foetus is usually recommended. As it is a life-threatening condition, expectant management carries a risk of sudden lifethreatening intraabdominal bleeding and a generally poor foetal prognosis. ${ }^{5}$ Proper pre-operative evaluation and diagnostic techniques can help ensure a timely diagnosis.

\section{CASE REPORT}

Mrs XX G2P0+1 was admitted to the hospital with h/o amenorrhoea for two and a half months, with the chief complaints of pain abdomen for one week which was severe that day for which she attended emergency. She had a past history of ectopic pregnancy one year back for which laparotomy followed by salpingectomy was done on examination, vitals were normal, P/A she had a 14 weeks size uterus. There was tenderness in the left iliac fossa. On $\mathrm{P} / \mathrm{V}$ examination, uterus was not felt separately, OS was closed. There was no bleeding per vagina.

Patient was put on analgesics and was relieved of pain. USG next morning showed a single live intra uterine pregnancy with a solid retro gestational sac collection, with a CRL of $11 \mathrm{~W} 3 \mathrm{D}$, with adequate amniotic volume. 
HB was $10.2 \mathrm{gm} \%$, rest all other investigations were normal. For the next two days patient continued to have episodic pain which was relieved with analgesics. Patient was prescribed folic acid, progesterone and analgesics.

On the third day of admission the pain increased, fundal size increased up to 18 weeks size and there was tenderness over abdomen with mild tachycardia. A repeat USG done on Day 4 showed viable pregnancy with the collection and a differential diagnosis of a fibroid undergoing red degeneration was given. Patient was managed conservatively for the next three days. On day 8 , a repeat USG was done which showed missed abortion with central placenta previa with large retro placental collection and suspected placental invasion was given as the myometrium could not be delineated. A repeat $\mathrm{HB}$ on day 8 , showed the level to be $8.7 \mathrm{gm} \%$. With the rising fundal height and drop in $\mathrm{Hb}$ levels, a decision for laparotomy was taken. On day 9, patient underwent laparotomy under general anaesthesia.

\section{Intraoperative findings}

On opening the abdomen and peritoneum, the gestational sac was found ruptured and the foetus was in the peritoneal cavity (Figure 1). Abundant clots with placental tissue were seen in the peritoneal cavity. Bowel and omentum was found adherent to the placental tissue. Bleeding was present from all the surfaces of the placental tissue attached to the bowel and peritoneum.

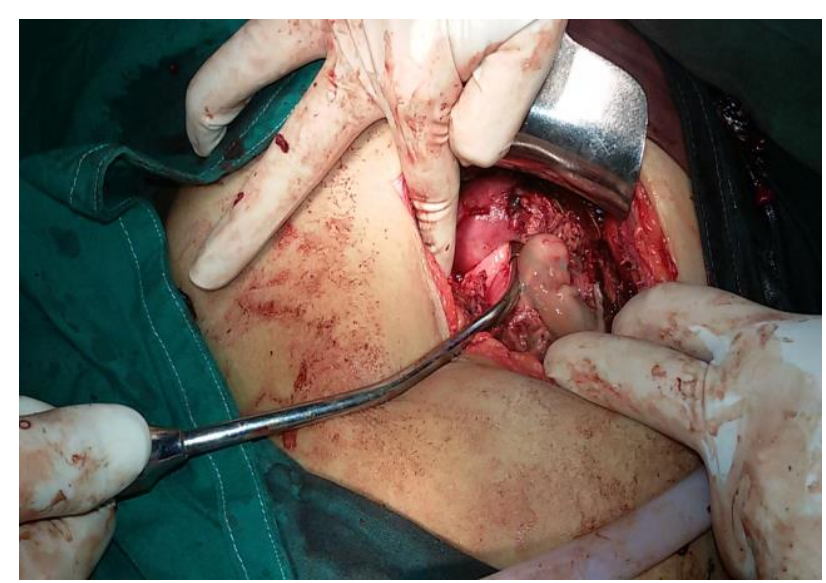

Figure 1: Fetus in peritoneal cavity.

Uterus was not visualized because of bleeding and adhesions. Hot packing was given. A vaginal examination was done with sounding of the uterus and fundus was felt. Adhesiolysis was done and after removing the placental tissue, the uterus could be visualised (Figure 2). Right tube could not be visualised in totality (post salpingectomy). Right ovary was normal. Left tube and ovary were normal. A diagnosis of secondary abdominal pregnancy was made based on the intra op findings. As much placental tissue as possible was removed from omentum and bowel adhesions. Haemostasis was secured, intraperitoneal wash given and drain was kept in situ. Abdomen was closed in layers. Two units' blood were given intraoperatively. Serum beta HCG was sent and level was $2052 \mathrm{mIU} / \mathrm{ml}$. Post op period was uneventful and patient is planned to be followed up with serum Beta HCG levels.

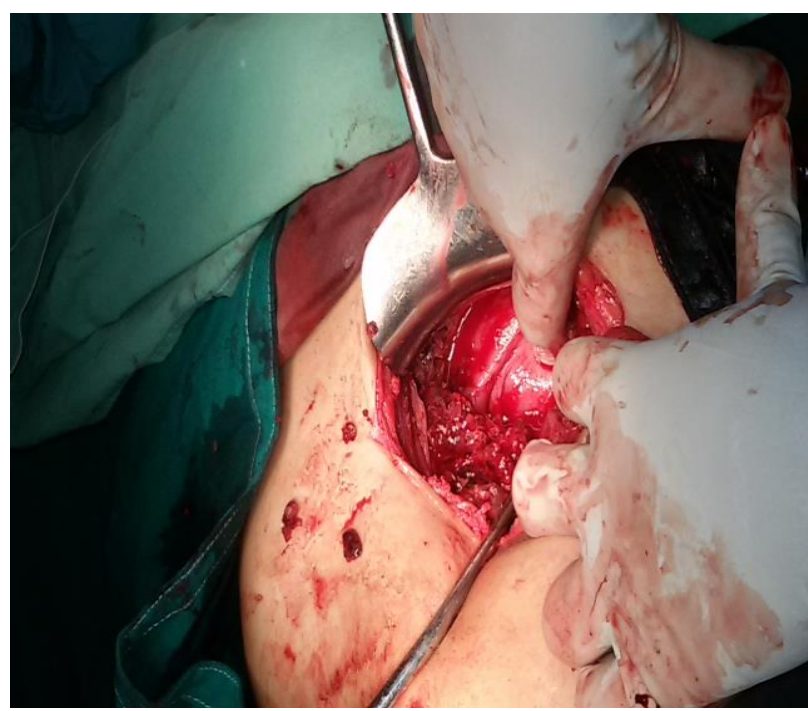

Figure 2: Intact uterus.

\section{DISCUSSION}

Abdominal pregnancy is a rare obstetric complication with high maternal and perinatal morbidity and mortality. ${ }^{4}$ As early rupture of tubal ectopic pregnancy is the usual antecedent of a secondary abdominal pregnancy; a suggestive history can usually be obtained. These include spotting or irregular bleeding along with abdominal pain, nausea, vomiting, flatulence, constipation, diarrhoea and abdominal pain, all in varying degrees. Foetal malpresentation, extreme anterior displacement of the cervix, failure of spontaneous onset of labor and artificial induction of labor are common complications. Appreciable cervical effacement is also unusual in these patients. Small fetal parts may be palpated through the vaginal fornices and identified clearly outside the uterus. ${ }^{5}$ The patient with an abdominal pregnancy typically presents with constant abdominal pain; two of our patients sought medical attention for this and initial evaluation showed them to be hemodynamically stable. About $50 \%$ of diagnoses are missed on ultrasound but MRI and CT are both excellent diagnostic tools to diagnose secondary abdominal pregnancy. ${ }^{3-5}$

In our case the past history of an ectopic pregnancy gave the diagnosis of secondary abdominal pregnancy.

During laparotomy, the clinician must make a decision concerning the fate of the placenta. Post-operative maternal morbidity will probably be lessened by total removal of the placenta if this is technically feasible and this should be possible using proper pre-operative treatment modalities such as embolization or systemic methotrexate. If vascular attachment involves major vessels or vital structures, the organ should be left 
undisturbed. ${ }^{8}$ Post-operative methotrexate has been administered by some for placental absorption but it leads to accumulation of necrotic tissue due to accelerated placental absorption and increases morbidity. ${ }^{5-7}$ Retention of the placenta in situ is not without its attendant risks and postoperative morbidity can be substantial.

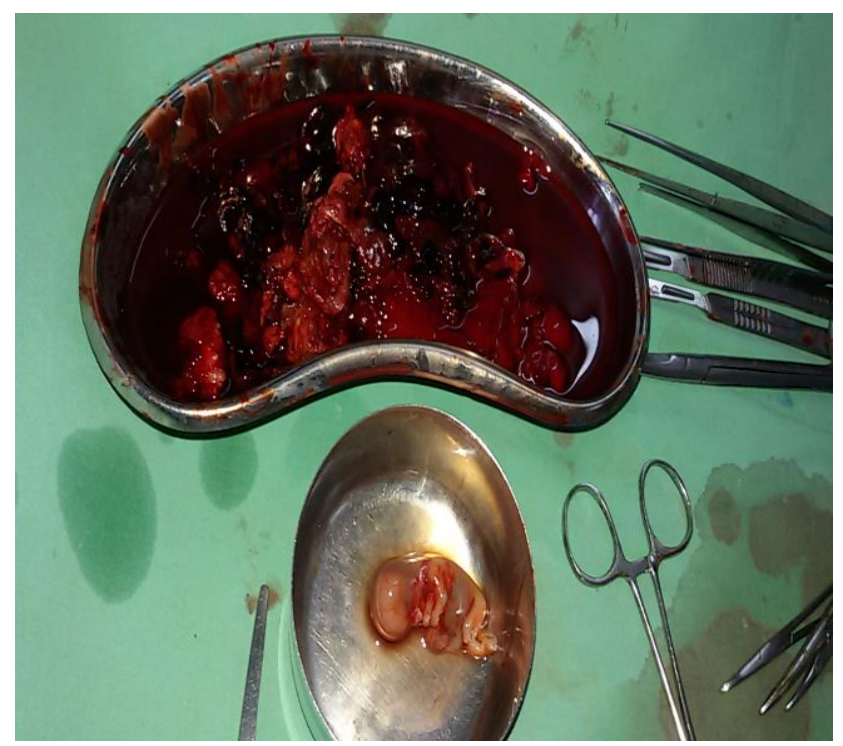

Figure 3: Fetus with placental tissue and clots.

\section{CONCLUSION}

Proper pre-operative evaluation and pre-operative systemic methotrexate, assurance of sufficient blood products, availability of a multidisciplinary surgical team and proper operative techniques in managing abdominal pregnancy can reduce maternal morbidity.
Funding: No funding sources Conflict of interest: None declared Ethical approval: Not required

\section{REFERENCES}

1. Worley KC, Hnat MD, Cunningham FG. Advanced extra uterine pregnancy: diagnostic and therapeutic challenges. Am J Obstet Gynecol. 2008;198:297:e1297-7.

2. Studdiford WE. Primary peritoneal pregnancy. Am J Obstet Gynecol. 1942;44:487-91.

3. Atrash HK, Friede A, Hogue CJ. Abdominal pregnancy in the United States. Frequency and maternal mortality. Obstet Gynecol. 1987;69:333.

4. Lastra A, Ruiz Bedoya JA, Jiménez Balderas EA. Abdominal pregnancy with fetal survival. A report of 2 cases. Ginecol Obstet Mex. 1993;61:348-50.

5. Cunningham GF, Levine KJ, Bloom SI. In Williams Obstetrics. 22 $2^{\text {nd }}$ edition. London: Prentice Hall International (UK). 2005;265-6.

6. Rahaman J, Berkowitz R, Mitty H. Minimally invasive management of an advanced abdominal pregnancy. Obstet Gynecol. 2004;103:1064-8.

7. Roberts RV, Dickinson JE, Leung Y, Charles AK. Advanced abdominal pregnancy: still an occurrence in modern medicine. Aust NZ J Obstet Gynaecol. 2005;45:518-21.

8. Hallatt JG, Grove JA. Abdominal pregnancy: a study of twenty-one consecutive cases. Am J Obstet Gynecol. 1985;152:444-8.

Cite this article as: Roy I, Choubey N. Abdominal pregnancy-a case report. Int J Reprod Contracept Obstet Gynecol 2021;10:3614-6. 